\title{
Polyaniline and their Conductive Polymer Blends: A Short Review
}

\author{
Saiful Izwan Abd Razak ${ }^{1}$, Wan Aizan Wan Abdul Rahman ${ }^{1 *}$, Shahrir Hashim ${ }^{1}$, Mohd Yazid Yahya ${ }^{2}$ \\ ${ }^{1}$ Polymer Engineering Department, Faculty of Chemical Engineering, Universiti Teknologi Malaysia, 81310 Skudai, Johor, Malaysia \\ ${ }^{2}$ Centre for Composites, Universiti Teknologi Malaysia, 81310 Skudai, Johor, Malaysia \\ Received 10 November 2012, Revised 12 February 2013, Accepted 26 February 2013, Available online 3 March 2013
}

\begin{abstract}
This short review discusses recent research regarding conductive polymeric blends containing polyaniline (PANI). Conducting PANI was reviewed in view of their properties to be used as a conducting component in several polymer matrix composites. Conductive PANI blends shows promise since the discovery of conducting polymers itself. These composite materials have introduced practical applications in various fields, including electromagnetic shielding and microwave absorption, static electricity dissipation, conducting membrane materials, conductive paint coatings and sensor materials. Highlights were made on PANI containing composites of polyethylene, polyamides, rubbers and elastomers, including other conventional thermoplastics and thermosets. Their electrical properties (percolation threshold and resistivity), blends preparation, drawbacks and potential usage were discussed in detail.
\end{abstract}

| Polyaniline | Conducting polymers | Percolation threshold | Conductive composites |

( 2013 Ibnu Sina Institute. All rights reserved. http://dx.doi.org/10.11113/mjfas.v9n2.86

\section{INTRODUCTION}

Polyaniline (PANI) is one of the most interesting conducting polymers due to its low cost, good processability, environmental stability, unique active conduction mechanism [1] and reversible control of conductivity both by charge-transfer doping and protonation [2]. PANI can exist in a number of different oxidation states. It can exist as the fully oxidized pernigraniline via protoemaraldine to the fully reduced leucoemaraldine. The $50 \%$ oxidized polymer had been termed emaraldine [3]. PANI becomes conducting when the emaraldine base (EB) form is protonated and charge carriers are generated. The protonated emaraldine salt (ES) has conductivity many orders of magnitude higher than that of common polymers but lower than that of typical metals. Generally, ES and EB forms of PANI can be interchanged by doping and dedoping with acid and base [4] and the conductivity of PANI can be controlled, ranging from $10^{-11}$ to $10^{3} \mathrm{Scm}^{-1}$ [5]. Efforts have shifted to their use as conducting polymer composites or blends with common polymers. This trend has been driven by the need to replace traditional inorganic conducting fillers and to improve the processibility of conducting polymers, along with their mechanical properties and stability.

These composite materials have introduced conducting polymers to practical applications in different fields, including electromagnetic shielding and microwave absorption [6], static electricity dissipation [7], heating elements (clothing, wall papers, etc.) [8], conducting membrane materials [9], paint coatings for anticorrosion protection [10], and sensor materials [11]. This short review will survey the results of studies of the PANI blended composites to elucidate the application and feasibility of each method. Emphasis was made on composites of PANI with conventional polymers.

\section{PREPARATION METHODS}

The choice of the best method to produce composites with specified characteristics remains an unresolved problem. The problem arises because the processing method may significantly determine the properties of the manufactured composite materials. Known methods to produce PANI containing composites may be essentially reduced to two distinct groups: (1) synthetic methods based on aniline polymerization in the presence of or inside a matrix polymer, and (2) blending methods to mix a previously prepared PANI with a matrix polymer. The synthetic direction is probably preferable if it is necessary to produce inexpensive conducting composites, due to use of inexpensive aniline instead of more expensive PANI, or when there is a need to form composites which have conductivity only in a thin surface layer. Good homogeneity and a low percolation threshold characterize these composites. On the other hand, blending methods sometimes seem to be more technological desirable from the standpoint of large-scale production, particularly in the case of melt procession techniques. Blending methods will be probably become very practicable when techniques to 
produce inexpensive, nano-sized PANI are well developed. By synthetic methods it can be described as

- Dispersion polymerization of aniline in the presence of a matrix polymer in a disperse or continuous phase of a dispersion [12];

- Chemical in situ polymerization of aniline in a matrix or in a solution with a matrix polymer [12];

- Electrochemical polymerization of aniline in a matrix covering an anode [13];

- Polymer grafting to a PANI surface [14];

- Copolymerization of aniline with other monomers resulting in the formation of soluble aniline copolymers, which can be considered as a composite polymer [15].

Meanwhile blending method includes

- Solution blending soluble matrix polymers and substituted PANI [16];

- Solution blending soluble matrix polymers and PANI doped by functionalized protonic acids (counterion-induced processibility) [17] ;

- Solution blending undoped PANI with polymers soluble in amide or acidic solvents [18] ;

- Dry blending followed by melt processing (mechanical mixing of doped PANI with thermoplastic polymer, then molded in a hot press or extruder) [19];

\section{CONDUCTIVE POLYMER BLENDS OF PANI}

\subsection{Polyethylene and Polypropylene}

Ultra high molecular weight (UHMW) polyethylene and PANI blends were prepared by using mixture of $\mathrm{m}$ cresol and decaline that form films. The reported threshold was at $1 \mathrm{wt} \%$ with conductivity up to $10^{-6} \mathrm{~S} / \mathrm{cm}$. However, the integrity of the tensile strength of the blend was drastically lost (from 3.3 to $0.5 \mathrm{MPa}$ ) after $10 \mathrm{wt} \%$ of PANI. The elongation at break reduced as expected with a phase separation of PANI at 10wt\% [20]. Chipara et al., 2003 [21] prepared blends of PANI and low density polyethylene (LDPE) by dispersing the PANI powders in a roll mill at 80 ${ }^{\circ} \mathrm{C}$. The percolation was broad (up to $40 \mathrm{wt} \%$ PANI). This result reflects the usual difficulties related with the mixing of the components by mechanical methods. This was due to the antioxidant character of PANI and amplified by the fact that during the mechanical mixing of components, a high concentration of free radicals is produced. The tensile strength dropped to nearly $40 \%$ with $40 \mathrm{wt} \%$ PANI, similarly can be said to elongation at break. The behavior is governed by the poor adhesion between the PANI particles and the polymeric matrix. It was described that a preferential location of PANI chains in PE crystalline domains occurred as shown in Figure 1.

Another work on LDPE/PANI blend [22] described the use of gallic acid ester (Figure 2) as a compatibilizer between PANI and LDPE in pursue of lowering the percolation threshold by the use of extrusion. The compatibilizers interaction with LDPE is facilitated by the presence of alkyl substituents while the polar part interacts through $\mathrm{H}$ bonding with PANI. This gave rise to the existence of double percolation (PANI in compatibilizer and PANI in LDPE), which had been mention theoretically earlier by Knackstedt et al., 1996 [23] that would reduced the overall percolation. The percolation was achieved at $3 w t \%$ of PANI.

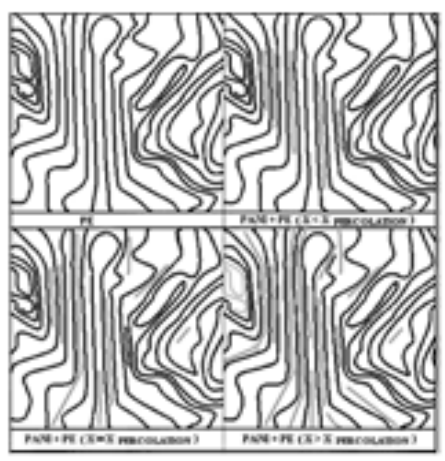

Fig. 1. Schematic representation of percolation in PE/PANI composites [21]

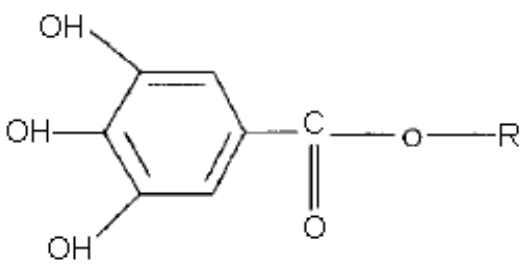

Fig. 2. General formula of gallic acid ester

Polypropylene (PP)/PANI blended film by dissolution of xylene with dodecyl benzene sulfonic acid (DBSA) [24] revealed a microscopic distinct PANI phase with interconnected structure (20 wt $\%$ ) at the matrix surface as observed by optical microscope. The conductivity increases from $10^{-14} \mathrm{Scm}^{-1}$ at $5 \mathrm{wt} \%$ PANI to $10^{-4} \mathrm{Scm}^{-1}$ at $15 \mathrm{wt} \%$ PANI. No percolation was observed. The storage moduli of the matrix host decreased with temperature without any dramatic loss below $20 \mathrm{wt} \%$. Fryczkowski et al., 2006 [25] prepared solid state protonation of PANI by phenylophosphonic acid (PPA) followed by thermal pressing with PP. Lauryl gallate was used as to increase its miscibility. The optimum PPA content was recorded at 13.5 wt $\%$, while the optimum lauryl gallate was at $10 \mathrm{wt} \%$. The highest conductivity was found for the blend in which the smallest crystallites of PP were formed. Apparently, small crystallites favour the development of conductive pathways in crystalline host blends. 


\subsection{Polyamide}

Polyamide 6 (PA6)/PANI blend film had been prepared by using formic acid. The formic acid acts as solvent and protonating medium. Formic acid, being a rather weak acid, is not a very good protonating agent for PANI (tendency to deprotonate). Additional dopant was used in the PA6/PANI in formic acid solution to exchange with the formic acid doped PANI. The use of additional dopant exhibits no phase separation and significant deprotonation [26]. Similarly, blend of PA6/PANI showed a maximum conductivity up to $0.2 \mathrm{Scm}^{-1}$ at $50 \mathrm{wt} \%$ of PANI. The conductivity of the film increased after being stretched to varying degrees [27]. PA6 film filled with aniline monomer could be polymerized by immersion in dopant and oxidant solution to produce PA6/PANI film. The conductivity of the blend decays at elevated temperatures in air, more pronounced at $150^{\circ} \mathrm{C}$ and higher. The polymerization of PANI within the PA6 suggested that variation of crystal transition of PA6 exists with presence of PANI [28]. The same group later on described a reduction of doping ability of PANI by the existence of hydrogen bond between the PANI and PA6. It has been found that the thermal cross-linking reaction of PANI (quinoid ring and imine group) could be reversibly by chemical doping and dedoping process [29]. An in situ prepared camphor sulfonic acid (CSA) doped PA6/PANI blend showed a better dispersion within the matrix. The in situ blend had higher conductivity compared to samples prepared by physical blending at $10 \mathrm{wt} \%$. At higher PANI content (10 wt\%), the in situ blend showed lower conductivity due to the greater influence of the formic acid medium. Furthermore, the use of formic acid in the in situ synthesis resulted in a loss of electroactivity of the blend [30]. Another form of nylon, polyamide 6, 6 (PA 6,6) which in fibrous form had been solution blended with PANI by in situ polymerization of PANI. The PANI particles were dispersed homogenously throughout the fibrous matrix surfaces. No coating formation was observed. The conductivity was highest at $20 \mathrm{wt} \%$ of aniline which around $10^{-2} \mathrm{Scm}^{-1}[31]$. Zhang et al., 2001 prepared PA12/PANI blend fibers by wet spinning in concentrated acid solution. The author revealed that the crystal structure of the PA12 is not disrupted, and that there is no mixing on a molecular level between the two components. The PANI resides mainly in the inter-spherulitic region of the nylon host. The percolation threshold of the fibers was about $5 \mathrm{wt} \%$ and the conductivity was from $10^{-6}$ to $10^{-1} \mathrm{~S} / \mathrm{cm}$ with different PANI fraction from 3 to $16 \mathrm{wt} \%$. Increasing draw ratio of the fibers seemed led to higher conductivity [32]. A work on PA11/PANI has shown that $5 \mathrm{wt} \%$ of PANI suggested narrower inter-planner spacing between the PA11 chains compared to $1 \mathrm{wt} \%$ of PANI. As the concentration of PANI is increased (5 wt\% PANI), the complex is formed between the PA11 and PANI (PANI co-ordination with oxygen of the amide group) which further pushed the chains of PA11 so that the amide group goes out of plane as to form a tightly bound hydrogen bonds [33].

\subsection{Poly (vinyl alcohol), Polycarbonate, Poly (methylmethacrylate)}

Poly(vinyl alcohol) (PVA) is a well-known water soluble polymer with high transparency, very good flexibility and wide commercial availability. It was shown that PVA could act as an efficient steric stabilizer for the synthesis of PANI in stable aqueous solution/dispersion form [34]. The composite shows satisfactory storage stability with good film forming. The blend exhibits significant EMI shielding capability and potential for sensing moisture and methanol vapour. Another method to produce stable PVA/PANI composite is by a unique method of aniline polymerization in the presence of DBSA, through an anilinium-DBSA complex [35]. PANI-DBSA polymer blends were obtained by mixing an aqueous PANI-DBSA dispersion with an aqueous emulsion of the matrix polymer, followed by water evaporation. These blends exhibit electrical conductivity at a very low PANI-DBSA content (0.5 wt.\%). The hydrophobic tails of free and bonded DBSA molecules are arranged in a way that they all turn to each other, while the hydrophilic groups of the free DBSA turn to the aqueous phase Figure 3.

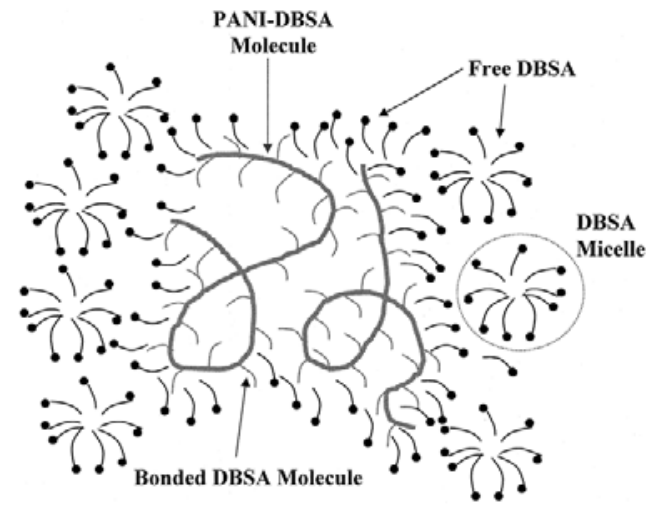

Fig. 3. A schematic model of aqueous dispersions of polyaniline with DBSA [35].

Mirmohseni et al., 2003 [36] meanwhile produced a stable PVA/PANI composite film by chemical polymerization of aniline in media containing PVA. Oxidation of aniline resulted in a stable water based polyaniline dispersion, which can be cast to form a mechanically robust film. The electrical conductivity of the films increased with increasing amount of polyaniline to a high value of $2.5 \mathrm{Scm}^{-}{ }^{1}$. Cyclic voltammograms revealed that the composite materials are electroactive. Polycarbonate (PC)/PANI-DBSA composite was prepared by an inverted emulsion polymerization in which DBSA played both roles of surfactant and dopant [37]. Fourier transform infrared spectroscopy for the composite showed the existence of hydrogen bonding between PANI and PC which caused the increase of glass transition temperature with PANI content. Moreover, the electrical conductivity 
increased around the glass transition temperature because the PANI chains contacted more frequently and facilitated the electron transfer through the hydrogen bonding between PANI and PC. In addition, it was proved by mechanical property that tensile strength of the composite decreased with PANI content because PANI functioned as a defect in PC matrix and the tensile modulus continuously increased because PANI had a higher rigidity of molecules. A conducting composite using PANI and PC was prepared by a blending method [38]. Chloroform was used as a solvent in the blending. The PANI was protonated using DBSA. A sulfonic group was introduced into the structure of the PC in order to enhance the coulombic interaction between each phase of the composite. The electrical conductivity increased to $7.5 \mathrm{Scm}^{-1}$ with the amount of PANI complex protonated with DBSA having a long alkyl chain. The sulfonation effect not only lowers the percolation threshold in the composite, but also increases the electrical conductivity and mechanical properties. Poly(methylmethacrylate) (PMMA) has been reported to have excellent optical properties such as very good transparency in the visible region and fairly good photoluminescence emission. It has been reported that PMMA/PANI composite using bulk polymerized PMMA significantly improves the mechanical strength and processibility of PANI [39]. It is observed that the photoluminescence intensity increases with increase in the PMMA content in the composite, possibly due to greater chances of exciton formation and subsequent radiative decay to the ground state. The DC electrical conductivity of these composites falling in the high semi conducting region (0.044-0.3725 S/cm) coupled with the high photoluminescence emission intensity highlights the prospects of application of these composites as emissive layers in polymer light emitting devices. PANI was blended with conventional industrial PMMA thermoplastics in order to obtain an electrically conductive polymer blend with adequate mechanical properties. Processing these polyblends into foams yields a porous conductive material that exhibits immense application potential such as dynamic separation media and low-density electrostatic discharge protection. Such method was reported by using two phase batch foaming setup [40].

\subsection{Rubbers and Elastomers}

Conventional electrically conductive elastomers usually contain graphite, coarse carbon black or powdered metals [41]. Blends of poly(butadiene-co-acrylonitrile) elastomer (NBR) and DBSA-doped PANI have been prepared by solution mixing by the use of chloroform. Blends prepared using NBR with 48 wt\% acrylonitrile (ACN) had the lowest percolation thresholds with the lowest level of phase separation. The conductivity of the blend was up to $10^{-2} \mathrm{Scm}^{-1}$ [42]. Similar blend of PANI and NBR showed better conductivity by using in situ emulsion polymerization instead of mechanical mixing (roll milling) at the same wt\% of PANI [43]. PANI blended with ethylene-propylene-diene (EPDM) rubber was prepared by three doping method 1) grinding in mortar, 2) solution mixing and 3) reactive processing (doping during mechanical mixing). All three methods showed formation of networks which inhibits the EPDM's solubilisation. Samples prepared by reactive mixing showed higher tensile strength than the other two methods. Meanwhile, the percolation thresholds were achieved at $30 \mathrm{wt} \%$ independent of the doping method [44]. Thermal degradation of solvent casted EPDM/PANI blend showed two stages of degradation. Whereby, the second step was described as the degradation of bound dopant of PANI and the elastomer [45]. Polystyrene-block-poly(ethylene-ranbutylene)-block-polystyrene (SEBS) and PANI blend was prepared by solution casting using toluene and in situ method. The percolation threshold occurred at $20 \mathrm{wt} \%$ for both methods (solution and in situ, 17.2 and $18.7 \mathrm{Scm}^{-1}$, respectively.). The in situ blend had higher conductivity than the solution casting as it reached its percolation and above [46]. Blend of PANI, EPDM and organoclay prepared by an internal mixer revealed PANI aggregates throughout the elastomer matrix. The blend exhibit conductivity in the range of $10^{-3} \mathrm{Scm}^{-1}$ for $40 \mathrm{wt} \%$ PANI and microwave attenuation values of $80 \%$ in the frequency range of $8-12 \mathrm{GHz}$ [47].

\subsection{Epoxies}

The first conductive epoxy (EP)/PANI composite was prepared by mechanical mixing of doped PANI with the EP resin [48]. It was shown that that the PANI percolated in $\mathrm{EP}$ at 10 vol.\% with conductivity ranges from $10^{-8}$ to $10^{-3} \mathrm{Scm}^{-1}$. It was first demonstrated the possibility of curing EP resin with PANI-sulfate (doping by the sulfate ion of APS (ammonium presulfate)). For a 1:1 ratio of PANI to PANI-sulfate, the EP resin could be cured in 4.5 min at temperature around $180{ }^{\circ} \mathrm{C}$ [49]. Paste-like PANIDBSA (with excess DBSA) has been demonstrated to improve the dispersion of the PANI in EP. PANI paste exhibits lower percolation threshold in EP resin than PANI powder. This was mainly owing to the existence of excess DBSA in the paste, which acts as a plasticizer, thus much better dispersion was obtained. However it was found out that excess of DBSA retards the curing reaction of resin and hardener. Figure 4 shows the scanning electron microscope (SEM) images of the EP with 60 wt.\% of PANI paste [50].

Oligomeric PANI exhibited much better compatibility with EP resin compared to the high molecular weight PANI. The EP/PANI composites film $(0.1 \mathrm{~mm}$ thick) showed a very low threshold PANI for electrical conduction with conductivity in the range of $10^{-5}$ to $10^{-2}$ $\mathrm{Scm}^{-1}$. The transmission electron microscope (TEM) morphology (Figure 5) showed fine microscopic dispersion of oligomeric PANI. Furthermore tensile strength of the EP/PANI film reduced substantially compared to the neat EP film [51].

It has been shown that the electrical conductivity of EP/PANI composites increased with the addition of PANI 
(doped with DBSA), reaching a value higher than $10^{-7} \mathrm{Scm}^{-}$ ${ }^{1}$ with 10 wt.\% of PANI [52]. In term of the composites mechanical properties, the flexural strength and modulus were not significantly affected by the addition of up to 7 wt.\% of PANI. However, the presence of $10 \mathrm{wt} . \%$ in the blends leads to an abrupt decrease in the values of those two properties (70 $\mathrm{MPa}$ and $2 \mathrm{GPa}$, for flexural strength and modulus respectively). It was described that the type of hardeners used to cure EP plays a crucial role to obtain a conductive EP/PANI composites [53]. The alkaline type hardeners (amine and imidazole) showed very low conductivity, close to that of neat EP, even at high PANI concentration. It was explained that dedoping of ES to EB occurred during the mixing of EP with alkaline type hardeners due to basic character of the curing agents. Meanwhile the acidic type curing agent $\left(\mathrm{BF}_{3}-\mathrm{complex}\right.$ catalytic and anhydride) seemed to support the conductive features of PANI in the EP resin. Anhydride curing revealed lower conductivity despite of its acidic character which was related to its curing action in the presence of PANI. It was found later on that region rich with PANI were formed in the EP matrix at concentrations of PANI above the threshold (5 wt.\%) and might affects the curing reactions as seen in Figure 6 [54].

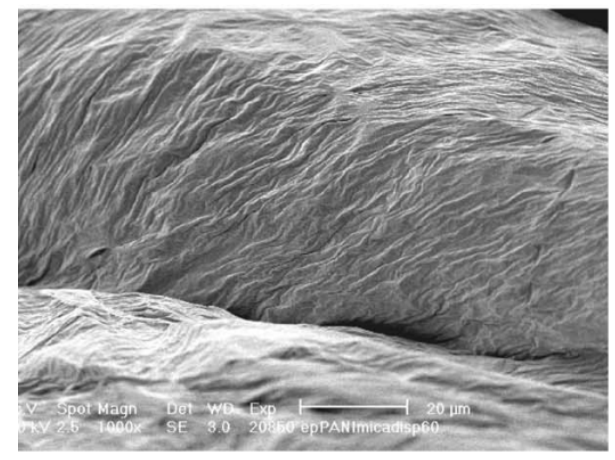

Fig. 4. SEM micrograph of EP with 60 wt.\% PANI paste [50].

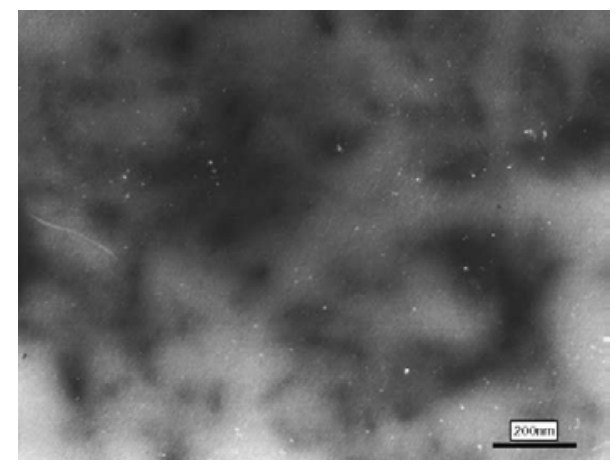

Fig. 5. TEM micrograph of EP with 1 phr of oligomeric PANI [51].

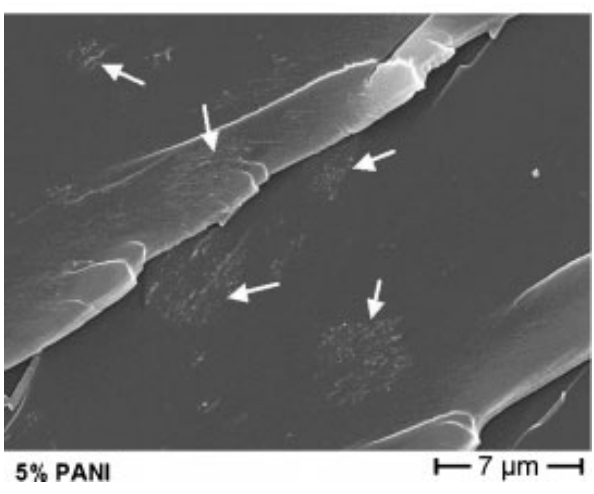

Fig. 6. SEM image of the PANI-DBSA-rich regions (indicated by arrows) [54].

The EP resin could be cured by PANI nanorods within liquid crystalline epoxy matrix [55]. This can be owed to the amine functional group that reacts with epoxide through nucleophilic addition mainly justified by the effect of PANI loading on the heat of cure. The maximum conductivity was $10^{-3} \mathrm{Scm}^{-1}$ at $20 \mathrm{wt} . \%$ of PANI. Also it is possible to prepare EP composites containing doubly doped PANI (DBSA and p-toulene sulfonic acid (p-TSA)). The maximum conductivity was obtained at $10^{-5} \mathrm{Scm}^{-1}$ at 7.5 wt $\%$ of PANI and decreased at higher loading, due to dedoping of PANI caused by the anhydride curing agent [56]. PANI doped with DBSA could act as co curing agent for EP even in the presence of more reactive aliphatic amine hardeners [57]. The highest conductivity was $10^{-8} \mathrm{Scm}^{-1}$ at 30 wt.\% PANI loading. This low value was attributed to the dedoping caused by the aminic curing agent. Reduction of the hardener meanwhile increased the conductivity up $10^{-6}$ $\mathrm{Scm}^{-1}$ at $10 \mathrm{wt} . \%$ of PANI loading, mainly by reducing the deprotonation process. Another interesting strategy to prepare EP/PANI is by one step in situ polymerization. The aniline monomer would be polymerized within the resin to obtain more homogeneous conducting composites with more PANI loading. For example, the preparation of EP/PANI composites by in situ polymerization of protonated aniline salt monomer (aniline-CSA) within EP prepolymer. After curing with anhydride, this blend displayed a conductivity value around $10^{-6} \mathrm{Scm}^{-1}$ at $25 \mathrm{wt} . \%$ of PANI-CSA [58].

PANI structure; nanowires, nanofibers and particles played significant role in the EP matrix [59]. It showed that the conductive EP composite containing PANI nanowires had the lowest percolation threshold by comparison of that containing PANI particles or nanofibers. Different percolation thresholds of the EP/PANI composites indicate that the electrical conductivity depends strongly on the morphology of PANI. All the three types of EP/PANI composite show conductivity around $10^{-5} \mathrm{Scm}^{-1}$ at $15 \mathrm{wt} . \%$ loading. Depiction of the percolation condition is shown in Figure 7. A more recent study [60] showed that PANI nanoflakes percolated at 1.7 vol.\% in EP matrix reaching maximum conductivity of $10^{-3} \mathrm{Scm}^{-1}$. 

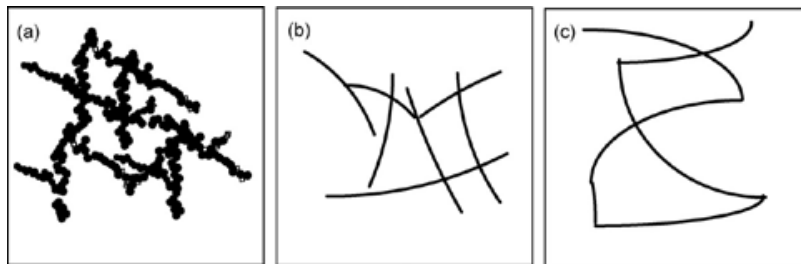

Fig. 7. Schematic representation of EP composites containing PANI with different morphologies. (a) Particles, (b) fibers, and (c) wires [60].

A new method for fabricating EP/PANI has been reported [61] using an absorption-transferring process, without involvement of solvent. Diglycidyl ether of bisphenol-A (DGEBA) was first modified to DGEBAaniline prepolymers. PANI nanoparticles were absorbed on the surfaces of the DGEBA-aniline droplets and diffused through the absorption-transferring process due to their high degree of attraction in water phase. The absorption of PANI component was suggested to react further with the epoxide group of DGEBA-aniline (curing). The output showed an outstanding value where the conductivity reached as high as $0.1 \mathrm{Scm}^{-1}$, while the percolation threshold was at $28 \mathrm{wt} . \%$. A comparison between physical mixtures (hand dispersed in mortar) and in situ prepared composites revealed a lower percolation threshold for the latter [62]. The in situ composites achieved conductivity around $10^{-2} \mathrm{Scm}^{-1}$ after the percolation being reached. The tensile strength of the composite decreased with increasing PANI, with reduction up to $30 \%$ (7 wt.\% loaded composite) compared to neat EP. A simple approach of introducing PANI nanowires doped with formic acid into EP was described [63]. The resulting conductive composites obtained better mechanical stability compared to that of EP/PANI-DBSA composites. Elastomeric EP/PANI using in situ method was also being investigated [64]. The polymerization was performed in swelled hydrophilic EP networks, in aqueous acidic condition containing oxidant and aniline. The method revealed PANI nanoparticles formation in the networks.

It has been described that the introduction of PANI reduces the mechanical properties of EP resin [62, 52]. Efforts are being made to reduce the mechanical deterioration of EP/PANI blend by reinforcing the composites with the incorporation of reinforcement fibers. Attempt to overcome this predicament is by reinforcing the EP/PANI blend with short carbon fibers and it was found out that the flexural modulus improved but minimally [65]. The reinforcing effect of the fibers were stable up to $7 \mathrm{wt} . \%$ of PANI. Another effort [66] was by incorporating the EP with PANI coated glass fiber. The tensile strength increased up to $27 \mathrm{MPa}$ (neat $\mathrm{EP}=35 \mathrm{MPa}$ ) compared to EP/PANI (10 MPa). On the other hand 20 wt.\% of PANI coated glass fiber was needed for percolation to occur. It was reported that the mechanical deterioration of EP/PANI blend could be limited by using natural fiber as the reinforcement, with the aid of suitable dopant [67]. EP composites containing PANI coated carbon nanotubes (CNTs) achieved percolation at $1 \mathrm{wt} . \%$ [68]. The reported tensile strength (at
1 wt.\%) loading was $61 \%$ higher than neat epoxy. Meanwhile the strength decreased as the loading increased above $1 \mathrm{wt} \%$. Similar trend was observed for the flexural properties. Also it was shown that functionalized magnetite nanoparticle was able to increase the tensile strength of EP filled with PANI reaching values slightly higher than that of neat EP [69]. It was suggested that the magnetite induced stiff interfacial layer with the matrix which hardened the EP deformation mechanism.

\section{CONCLUSION}

The utilization of PANI as conducting fillers in a polymeric system depends on many factors. The potential uses of such blends are in the areas of electronic components, coatings and structural bodies.

\section{ACKNOWLEDGEMENT}

The financial support provided by the Universiti Teknologi Malaysia through RUG grant $(04 \mathrm{H} 44)$ is gratefully acknowledged.

\section{REFERENCES}

[1] A. J. Heeger. J Phys. Chem B., 105 (2001), 8475-8491.

[2] A. G. MacDiarmid. Angew. Chem., Int. Ed., 40 (2001), 2581.

[3] W. J. Feast, J. Tsibouklis, K. L. Pouwer, L. Groenendaal, and E. W. Meijer, Polym., 37 (1996), 5017-5047.

[4] J. Stejskal, M. Omastová, S. Fedorova, J. Proke, and M. Trchová, Polym., 44 (2003),1353-1358.

[5] J. Stejskal, and R. G. Gilbert, Pure Appl. Chem., 74 (2002), 857 867.

[6] A. Bhattacharya, and A. De, Prog. Sol. State Chem., 24 (1996), 141-181.

[7] J. D. Stenger-Smith, Prog. Polym. Sci., 23 (1998), 57-79.

[8] A. K. Bakhshi, Bull. Mater. Sci., 18 (1995), 469-495.

[9] J. M. Davey, S. F. Ralph, C. O. Too, G. G. Wallace, and A. C. Partridge, React. Funct. Polym., 49 (2001), 87-98.

[10] B. Wessling, and J. Posdorfer, Electrochim. Acta, 44 (1999), 21392147.

[11] R. Gangopadhyay, and A. De, Sens. Actuator B., 77 (2001), 326329.

[12] S. P. Armes, M. J. Aldissi, M. Hawley, J. G. Beery, and S. Gottesfeld, Langmuir, 7 (1991), 1447-1452.

[13] J. Anand, S. Palaniappan, and D. N. Sathyanarayana, Prog. Polym. Sci., 23 (1998), 993-1018.

[14] Y. Chen, E. T. Kang, K. G. Neoh, P. Wang, and K. L. Tan, Synth. Met.,110 (2000), 47-55.

[15] B. Z. Zhao, K. G. Neoh, F. T. Liu, E. T. Kang, and K. L. Tan, Langmuir,16 (2000), 10540-10546.

[16] T. Vikki, L. O. Pietila, H. Osterholm, L. Ahjopalo, A. Takala, A. Toivo, K. Levon, P. Passiniemi, and O. Ikkala, Macromolecules, 29 (1996), 2945-2953.

[17] O. T. Ikkala, L. O. Pietilac, P. Passiniemi, T. Vikki, H. Osterholm, and L. Ahjopalo, Synth. Met., 84 (1997), 55-58.

[18] A. Andreatta, A. J. Heeger, and P. Smith, Polym. Commun., 31 (1990) 275-258.

[19] A. B. Kaiser, C. K. Subramaniam, P. W. Gilberd, and B. Wessling, Synth. Met., 69 (1995), 197-200.

[20] G. R. Valenciano, A. E. Job, and L. H. C. Mattoso, Polym., 41 (2000), 4757-4760. 
[21] M. Chiparaa, D. Huib, P. V. Notingherc, M. D. Chiparad, K. T. Laue, J. Sankarf, and D. Panaites, Compos. Pt. B., 34 (2003), 637645.

[22] J. P. Yang, P. Rannou, J. Plants, A. Profi, and M. Nechtschein, Synth. Met., 93 (1998), 169-173.

[23] M. A. Knackstedt and A. P. Roberts, Macromolecules 29 (1996), 1369-1371.

[24] I. L. Hosier, A. S. Vaughan, S. J. Patel, and S.G. Swingler, IEEE Transactions on Dielectrics and Electrical Insulations 8 (2001), 698704.

[25] R. Fryczkowski, C. Slusarczyk, and J. Fabia, Synth. Met., 156 (2006), 310-317.

[26] M. Zagorska, E. Harmasz, I. Kulszewicz, A. Pron, and J. Nizio, Synth. Met., 102 (1999), 1240.

[27] D. Abraham, A. Barathi, and S. V. Subramanyam, Polym., 37 (1996), 5295-5299.

[28] S. W. Byun, and S. S. Im, Polym., 39 (1998), 485-489.

[29] A. R. A. Schettini, R. C. D. Perers, and B. G. Soares,. Synth. Met., 159 (2009), 1491-1495.

[30] M. K. F. Mohamad, Synth. Met., 159, (2009), 119-122.

[31] A. R. Hopkins, P. G. Rasmussen, R. A. Basheer, B. K. Annis, and G. D. Wignall, Synth. Met. 95 (1998), 179-184

[32] Q. H. Zhang, H. F. Jin, X. H. Wang, and X. B. Jimng, Synth. Met., 123 (2001), 481-485

[33] S. A. Pande, D. S. Kelkar, and D. R. Peshew, Curr. Appl. Phys., 7 (2007), 590-595.

[34] R. Gangopadhyay, A. De, and G. Ghosh,. Synth. Met., 123 (2001), 21.

[35] Y. Haba, E. Segal, M. Narkis, G. I. Titelman, and A. Siegmann, Synth. Met., 110 (2000), 189.

[36] A. Mirmohsenia, and G.G. Wallace, Polym., 44 (2003), 3523.

[37] B. H. Jeon, M. H. Choi, and I. J. Chung, Synth. Met., 104 (1999), 95.

[38] W. Lee, Y. Kim, and S. Kaang, Synth. Met., 113 (2000), 237.

[39] M. Amrithesh, S. Aravind, S. Jayalekshmi, and R. S. Jayasree, J. Alloys Comp., 449 (2008), 176.

[40] A. D. Price, V. C. Kao, J. X. Zhang, and H. E. Naguib, Synth. Met., 160 (2010), 1832.

[41] G. Jiang, M. Gilbert, D. J. Hitt, G. D. Wilcox, and K. Balasubramanian, Compos. Pt. A., 33 (2002), 745-751.

[42] K. C. Yong, P. J. S. Foot, H. Morgan, S. Cook, and A. J. Tinker, Eur. Polym. J., 42 (2006), 1716-1727.

[43] B. G. Soares, G. S. Amorim, S. G. Souza, M.G. Oliveira, and J. E. P. da Silva, Synth. Met., 156 (2006), 91-98

[44] R. Faez, and M. A. De Paoli, Eur. Polym. J., 37 (2001), 1139-1143

[45] V. Schmidt, S. C. Domenech, M. S. Soldi, E. A. Pinheiro, and V. Soldi, Polym. Deg. Stab. 83 (2004), 519-527.
[46] G. M. O. Barra, R. R. Matins, K. A. Kafer, R. Paniago, C. T. Vasques, and A. T. N. Pires, Polym. Test., 27 (2008), 886-892.

[47] M. A. Soto-Oviedo, O. A. Aráujo, R. Faez, M. C. Rezende, and M. A. De Paoli, Synth. Met., 156 (2006), 1249-1255.

[48] P. Kathirgamanathan, Polym. 34 (1993), 2907-2908.

[49] S. Palaniappan, B. Sreedhar, and S. M. Nair, Macromolecular Chem. Phys. 202 (2001), 1227-1231.

[50] W. Jia, R. Tchoudakov, E. Segal, R. Joseph, M. Narkis, and A. Siegmann, Synth. Met. 132 (2003), 269-278.

[51] X.Yang, T. Zhao, Y. Yu, and Y. Wei, Synth. Met. 142 (2004), 5761.

[52] P. Tsotra, and K. Friedrich, Synth. Met. 143 (2004), 237-242.

[53] P. Tsotra, K. G. Gatos, O. Gryshchuk, and K. Friedrich, J. Mater. Sci. 40 (2005), 569-574.

[54] P. Tsotra, O. Gryshchuk, and K. Friedrich, Macromolecular Chem. Phys. 206 (2005), 787-793.

[55] J. Jang, J. Bae, and K. Lee, Polym. 46 (2005), 3677-3684.

[56] Q. Yang, A. Wei, and G. Cheng, Polym. Compos. 27 (2006), 201204.

[57] V. X. Moreira, F. G. Garcia, and B. G. Soares, J. Appl. Polym. Sci. 100 (2006), 4059-4065

[58] J. Lu, K. Moon, B. Kim, and C. P. Wong, Polym. 48 (2007), 1510 1516.

[59] Q. M. Jia, J. B. Li, L. F. Wang, J. W. Zhua, and M. Zheng, Mater. Sci. Eng. A. 448 (2007), 356-360.

[60] M. Oyharcabal, T. Olinga, M. Foulc, S. Lacomme, E. Gontier, and V. Vigneras, Compos. Sci. Technol. 74 (2013), 107-112.

[61] C. D. Liu, S. N. Lee, C. H. Ho, J. L. Han, and K. H. Hsieh, J. Phys. Chem. C. 112 (2008), 15956-15960.

[62] B. G. Soares, M. L. Celestino, M. Magioli, V. X. Moreira, and D. Khastgir, Synth. Met. 160 (2010), 1981-1986.

[63] S. I. A. Razak, W. A. W. A. Rahman, M. Y. Yahya, NANO. 7 (2012), 1250039.

[64] I. Krakovský, M. Varga, G. G. Ferrer, R. S. Serra, and M. S. Sánchez, J. Non-Cryst. Sol. 358 (2012), 414-419.

[65] P. Tsotra, and K. Friedrich, Compos. Sci. Technol. 64 (2004), 23852391.

[66] W. Jia, R. Tchoudakov, E. Segal, M. Narkis, and A. Siegmann, J. Appl. Polym. Sci. 91 (2004), 1329-1334.

[67] S. I. A. Razak, W. A. W. A. Rahman, and M. Y. Yahya, J. Compos. Mater. 10.1177/0021998313476527. (2013).

[68] J. Xu, P. Yao, Z. Jiang, H. Liu, X. Li, L. Liu, M. Li, and Y. Zheng, J. Appl. Polym. Sci. 125 (2012), E334-E341.

[69] H. Gu, S. Tadakamalla, Y. Huang, H. A. Colorado, Z. Luo, N. Haldolaarachchige, D. P. Young, S. Wei, and Z. Guo, Appl. Mater. Interf. 4 (2012), 5613-5624. 